Replaces California Institute of Technology Social Science Working Paper 158

\footnotetext{
The Journal of Pocitics. $41(1979)$ PS. $1081-1104$
}

\section{Majority Rule Models \\ and \\ Legislative Elections}

Morris P. Fiorina

Roger G. Noll

$\mathrm{T}$

I HE PRESENT GENERATION of political scientists possesses a wealth of knowledge about the logical structure of majority rule processes. Only thirty years ago Duncan Black began to publish a series of discoveries and rediscoveries about the properties of committee decisionmaking under majority rule. ${ }^{1}$ At almost the same time Kenneth Arrow proved a general result about the failings of collective choice mechanisms which included majority rule as a special case. $^{2}$ Anthony Downs insightfully applied these early findings to a political setting-that of free, two-party electoral competition ${ }^{3}$ In the 1960s Plott identified a set of necessary and sufficient (and restrictive) conditions under which majority rule processes produce stable outcomes. ${ }^{4}$ Sloss generalized this work. ${ }^{5}$ Meanwhile, in a

* An earlier version of this paper was presented at the Conference on Political Science and the Study of Public Policy, sponsored by the Department of Political Science of Michigan State University, May 15-17, 1978, Hickory Cormers, Michigan.

1 Duncan Black, "On the Rationale of Group Decision Making," in Journal of Political Economy 56 (1948), 23-34.

${ }^{2}$ Kenneth Arrow, Social Choice and Individual Values 2d ed. (New York: John Wiley \& Sons, Inc., 1963).

3 Anthony Downs, An Economic Theory of Democracy (New York: Harper, 1957).

${ }^{4}$ Charles R. Plott, "A Notion of Equilibrium and Its Possibility Under Majority Rule,” American Economic Review (1967), 788-806.

5 Judith Sloss, "Stable Outcomes in Majority Rule Voting Games," Public Choice (1973), 19-48. 
series of articles Davis, Hinich and Ordeshook elaborated the Downsian model of electoral competition. ${ }^{6}$ Hoyer and Mayer, ${ }^{7}$ and McKelvey ${ }^{8}$ summarized and synthesized much of this scattered literature.

The 1970s have seen developments on two fronts. On the substantive front majority rule models have been applied to legislative settings. ${ }^{9}$ More recently a succession of abstract analyses has explored the nature of the indeterminacy characteristic of majority rule processes. ${ }^{10}$ For two reasons, however, this latest line of research brings us to an impasse. First, it dashes earlier hopes of finding reasonably broad contexts in which majority rule equilibria exist. We now know that majority rule is generically unstable: the set of preference configurations which would support equilibria is vanishingly small. Second, earlier conjectures that the area of majority rule disequilibrium would be small and centrally located also prove unfounded. The area of indeterminacy usually turns out to be the entire policy space: majority rule can result in literally any outcome, depending on what proposals are matched and in what order. (See Appendix.)

This onward march of knowledge has created an embarrassing situation for those who wish to apply abstract majority rule models to real political contexts. Take the study of electoral competition. If a majority rule equilibrium exists (an exceedingly unlikely possibility, the theorists tell us), both candidates are expected to adopt

${ }^{6}$ For a review of this work see O. Davis and P. Ordeshook, "An Expository Development of a Mathmatical Model of the Electoral Process," American Political Science Review, 64 (1970), 426-448.

${ }^{7}$ Robert Hoyer and Lawrence S. Mayer, "Comparing Strategies in a Spatial Model of Electoral Competition," American Journal of Political Science, (August 1974 ), 501-523.

8 Richard D. McKelvey, "Policy Related Voting and Electoral Equilibrium," Econometrica 43 (1975), 815-843.

${ }^{9}$ For a review of developments up to 1975 see John Ferejohn and Morris Fiorina, "Purposive Models of Legislative Behavior," American Economic Association Papers and Proceedings, 65 (May 1975), 407-414.

${ }^{10}$ Richard McKelvey, "Intransitivities in Multidimensional Voting Models and Some Implications for Agenda Control," Journal of Economic Theory 12 (1976); N. Schofield, "Instability of Simple Dynamic Games," Review of Economic Studies, 45 (1978), 575-594; Linda Cohen, "Cyclic Sets in Multidimensional Voting Models," Social Science Working Paper No. 172, California Institute of Technology, August 1977; Linda Cohen and Steven Matthews, "Constrained Plott Equilibria, Directional Equilibria, and Global Cycling Sets," Social Science Working Paper No. 178, California Institute of Technology, September 1977. 
it and the election is expected to end in a tie. In the general case of no equilibrium, the candidate who moves last can always win. Several authors have suggested that incumbents, by virtue of their past records, are fixed points in the policy space. ${ }^{11}$ If so, the challenger can always defeat the incumbent. Thus, the application of abstract majority rule models to the study of electoral competition generates the conclusion that incumbents always lose, except for an occasional tie. This certainly qualifies as a nonobvious conclusion.

Rather than abandon the model at this point, some scholars have tried to make the best of the nonobvious conclusion. Downs, for example, developed his classic concept of "the coalition of minorities" after considering the hapless position of the incumbent party. ${ }^{12}$ Kramer embraces the nonobvious conclusion by constructing a dynamic model in which the stationary incumbent loses every election to the mobile challenger. ${ }^{13}$ The ensuing perpetual alternation of the two parties produces probabilistic convergence to a "centrally located" portion of the policy space.

Other researchers are less comfortable with the notion that incumbents always lose. To be sure, of the last three American presidents, one lost, one withdrew, and one evidently feared defeat sufficiently to engage in some extraordinary campaign practices. American state governors, moreover, have long been known to experience rough electoral sledding. ${ }^{14}$ But when we turn to American congressmen, British MPs, legislators of all stripes-the abstract theoretical prediction fails. Indeed, a major current area of inquiry in the legislative subfield is to explain the apparently overwhelming advantage of incumbency. Obviously, a variety of ad hoc explanations is available. Most of these focus on the invisibility of the challenger and the massive advertising campaigns of incumbents. But such explanations seem to conflict with the basic spirit of rational choice majority rule models, in that citizens are implicitly assumed to respond to advertising regardless of content. Granted, citizens may form their preferences on any basis they choose, but

${ }^{11}$ Kenneth Shepsle, "The Strategy of Ambiguity: Uncertainty and Electoral Competition," American Political Science Review 66 (1972), 555-568; Gerald H. Kramer, "A Dynamical Model of Political Equilibrium," Journal of Economic Theory, in press.

12 Downs, “An Economic Theory," Ch. 4.

13 Kramer, "A Dynamical Model."

${ }^{14}$ J. S. Turett, "The Vulnerability of American Governors, 1900-1969," The American Governor, ed. T. Beyle and O. Williams, (New York: Harper and Row, 1971). 
from an epistemological standpoint, to allow any and all preferences no matter how frivolous, is to trivialize the majority rule model. We doubt that many of its adherents would accept this way out.

Our contention in this paper is that existing majority rule models are not empirically wrong, just incomplete, and not incomplete because they ignore personal psychology, but incomplete because they ignore certain obvious and easily representable asymmetries between the candidates. Existing models presume that candidates compete for executive office. The citizen assumes that if one candidate (or Downsian "team") wins, one platform is implemented, whereas if the opponent wins, another platform becomes public policy. But the situation is different when the citizen chooses between candidates for legislative office. Public policy is determined by the winning candidate from one district acting in concert with the winning candidates from all other districts. Other things equal, this fact diminishes the incentive for a citizen to vote on the basis of the candidates' policy platforms and increases uncertainty about the policy consequences of the election. At the least, the citizen must decide how to deal with that uncertainty, and some ways of dealing with it may involve increased attention to other factors, factors not limited to mere name recognition or a pretty face.

This paper outlines an abstract model of voting in legislative elections. The model presumes that such elections take place in single member districts. Thus, it is principally applicable to the anglo-American democracies. Like the traditional models, this one too presumes a fully informed citizen, but information is assumed to extend beyond knowledge of a policy space and the candidates' positions within it. By "fully informed" we mean a citizen who understands the various ways in which legislative activities affect him, the essentials of legislative procedures and processes, and in particular the sources of influence within those processes. ${ }^{15}$

Our contention is that modern legislators do more than participate in the formulation of major national policies. Too often it is as-

15 We are aware that survey data on congressional electorates provide little support for such an assumption. For reasons not elaborated here we think such data underestimate the "true" state of awareness of the congressional electorate. But no matter, theories like that which follows do not have value only if they describe all citizens. If one is interested in examining marginal changes (of which a shift of 5 percent in the value of incumbency is an example), a theory which accurately describes only a marginal number of citizens may be sufficient to expla in important changes in political processes and public policy. 
sumed that electoral competition is limited to public goods space; this is an assumption which represents the most naive variant of classical democratic theory. Legislators from single-member districts always have indulged and continue to indulge in a second activity: they provide quasi-private goods to their districts. The term "pork barrel" conjures up visions of legislators scrambling to procure dams, locks, irrigation projects, and public buildings and facilities of all kinds. Moreover, the concept now extends to defense contracts, urban renewal and mass transit grants, neighborhood health centers, worker training and retraining centers-the list is lengthy.

In recent years yet a third activity has come to absorb an increasing amount of legislators' time and resources: casework. The large, complex bureaucracies of modern postindustrial societies increasingly impinge on the daily lives of their citizens. Regulations constrain what one can or can not do, and opportunities to profit from government programs are available to an ever larger portion of the citizenry. Although it is casually remarked that bureaucracies have a momentum of their own, it is true that legislators can have an impact on bureaucratic decisions, the more so the more discretionary those decisions. This is particularly true in the United States where legislatures play an important role in the budgetary process and show considerable independence in the authorization process as well. But legislative concern with bureaucratic decision making is evident even in such purportedly "rubber stamp" legislatures as the British Parliament. ${ }^{16}$

The model we propose simply acknowledges that legislators engage in each of the preceding three activities and that their constituents recognize that they do so. Furthermore, the model incorporates an asymmetry between incumbents and their challengers, an asymmetry which we regard as empirically true and deserving of explicit theoretical recognition.

\section{The Analysis: Three Concerns of the INFORMEd LegisLative EleCtorate}

We assume that citizens' evaluations of the three varieties of legislative activity are analytically separable, i.e., that we can

16 Bruce Cain, John Ferejohn and Mornis Fiorina, "The House is not a Home: MPs and their Constituencies," forthcoming, Legislative Studies Quarterly, November, 1979. 
examine each in isolation, then combine them under the assumption that no interactions override the separate analyses.

\section{The Policy Component of Congressional Voting}

In this section we denote the incumbent's platform by I, and the challenger's platform by $\mathrm{C}$. The standard electoral competition model presumes that the citizen's preferences for candidates can be represented by a utility function whose arguments are the policies advocated by the candidates and those preferred by the citizen, i.e., candidate $\mathrm{I}$ is preferred to candidate $\mathrm{C}$ only if $\mathrm{U}(\mathrm{I})>\mathrm{U}(\mathrm{C})$.

Perhaps the preceding formulation is a useful approximation of a citizen's evaluation of candidates for executive office. In that case the citizen presumably gets one platform or the other, although real governors, premiers and presidents find themselves stymied to some extent by legislatures, bureaucracies and courts. But what about the evaluation of candidates for legislative offices? The winning candidate joins other winning candidates ( 434 other winning candidates in the case of the U.S. House of Representatives) who collectively determine an outcome.

In a legislative election it seems more accurate to model the citizen as choosing between lotteries. With some probability, $\mathrm{p}(\mathrm{I})$, the incumbent will successfully implement his platform, and with complementary probability will not, and similarly for the challenger. The expected utilities of the legislative candidates based on policy stands are given by the following equations:

$$
\left.\begin{array}{l}
\mathrm{EU}\left(\mathrm{I}_{\mathrm{p}}\right)=\mathrm{p}\left(\mathrm{I}_{\mathrm{p}}\right) \mathrm{U}\left(\mathrm{I}_{\mathrm{p}}\right)+\left(1-\mathrm{p}\left(\mathrm{I}_{\mathrm{p}}\right)\right) \mathrm{U}\left(L \backslash \mathrm{I}_{\mathrm{p}}\right) \\
\mathrm{EU}\left(\mathrm{C}_{\mathrm{p}}\right)=\mathrm{p}\left(\mathrm{C}_{\mathrm{p}}\right) \mathrm{U}\left(\mathrm{C}_{\mathrm{p}}\right)+\left(1-\mathrm{p}\left(\mathrm{C}_{\mathrm{p}}\right)\right) \mathrm{U}\left(L \backslash \mathrm{C}_{\mathrm{p}}\right)
\end{array}\right\}
$$

Just what are the outcomes when the candidates fail to implement their platforms? Letting script $L$ signify "Legislature," the preceding equations posit that the citizen forms estimates of the outcomes the legislature produces (would produce) if the incumbent and challenger respectively were unsuccessful in implementing their platform. ${ }^{17}$ These $(L \backslash \mathrm{I})$ and $(L \backslash \mathrm{C})$ outcomes are basically those which obtain when the citizen's representative make no difference to the policy output of the legislature. In the remainder of

${ }^{17}$ In the real world success is seldom an all or nothing proposition as is assumed here. An altemate interpretation of (1) would be that the citizen expects a weighted average of the positions of the incumbent (challenger) and the rest of the legislature. 
this analysis we will assume that the citizen estimates that $(L \backslash I)=$ $(L \backslash C)=\mathrm{ND}$, the "no difference" outcome. ${ }^{18}$

At this point we abandon the symmetry which characterizes existing models by making the following assumption of incumbent effectiveness:

$$
\mathrm{p}\left(\mathrm{I}_{\mathrm{p}}\right)>\mathrm{p}\left(\mathrm{C}_{\mathrm{p}}\right)
$$

There are numerous empirical grounds on which to motivate this asymmetric assumption. Most obviously, the incumbent has a store of experience-first hand knowledge of how legislative processes work. Second, incumbents may hold formal positions of authority. Currently in the U.S. House, for example, there are about 175 committee and subcommitee chairmanships as well as a variey of party posts. In any given election probably 40 percent or more of American voters are evaluating an incumbent who holds a leadership post. Third, the odds are that incumbents are members of the majority party (roughly $2: 1$ in the U.S. House at present), and thus more able to influence the committee and party leadership. Of course, the assumption of incumbent effectiveness can go awry in some cases-particularly for minority party members-but in general we think it captures an important feature of legislative elections.

In choosing between incumbent and challenger the citizen determines whether $\mathrm{EU}\left(\mathrm{I}_{\mathrm{p}}\right)>\mathrm{EU}\left(\mathrm{C}_{\mathrm{p}}\right)$ or vice-versa, making no choice if they are equal. Thus the incumbent is preferred on policy grounds if

$$
\frac{p\left(I_{p}\right)}{p\left(C_{p}\right)}>\frac{U\left(C_{p}\right)-U(N D)}{U\left(I_{p}\right)-U(N D)}
$$

or if

$$
\text { when } \mathrm{U}\left(\mathrm{I}_{\mathrm{p}}\right)>\mathrm{U}(\mathrm{ND})
$$

$$
\frac{p\left(I_{p}\right)}{p\left(C_{p}\right)}<\frac{U\left(C_{p}\right)-U(N D)}{U\left(I_{p}\right)-U(N D)}
$$

$$
\text { when } U\left(I_{p}\right)>U(N D)
$$

18 This appears to be a harmless assumption. The only time it might be seriously in error would be if the legislature were divided evenly between the two parties. In this case which of the two candidates won in the district under consideration could determine the organization of the legislature, the identity of the prime minister, etc. 
TABLE 1

Candidate Preferences Based on Policy Component of Congressional Voting

Incumbent Ranked First:

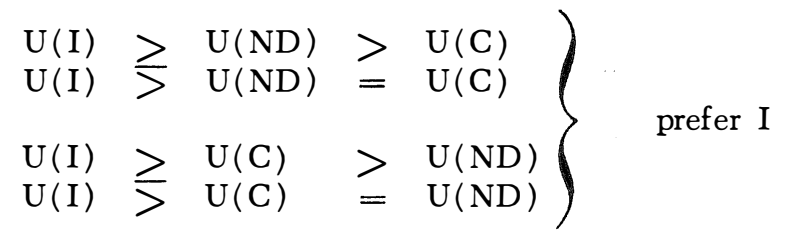

Incumbent Ranked Last:

$$
\left.\begin{array}{l}
\mathrm{U}(\mathrm{C}) \geq \mathrm{U}(\mathrm{ND})>\mathrm{U}(\mathrm{I}) \\
\mathrm{U}(\mathrm{C})>\mathrm{U}(\mathrm{ND}) \\
\mathrm{U}(\mathrm{ND}) \geq \mathrm{U}) \\
\mathrm{U}(\mathrm{ND}) \geq \mathrm{U}(\mathrm{C})>\mathrm{U}(\mathrm{I}) \\
\mathrm{U}(\mathrm{C})=\mathrm{U}(\mathrm{I})
\end{array}\right\} \quad \text { prefer } \mathrm{C}
$$

Incumbent Middle Ranked:

$$
\begin{aligned}
& \mathrm{U}(\mathrm{C}) \\
& \mathrm{U}(\mathrm{ND})>\mathrm{U}(\mathrm{I})>\mathrm{U}(\mathrm{ND})>\text { depends, IE favors I } \\
& \hline \mathrm{U}(\mathrm{C})-\text { depends, IE favors } \mathrm{C}
\end{aligned}
$$

Indifference:

$\mathrm{U}(\mathrm{I})=\mathrm{U}(\mathrm{C})=\mathrm{U}(\mathrm{ND}) \quad$ - indifference between $\mathrm{I}$ and $\mathrm{C}$

From the incumbency effectiveness (IE) assumption we know that $p\left(I_{p}\right) / p\left(C_{p}\right)$ is greater than one. This fact permits a determination of the candidate preferences produced by all but two of the possible preference orderings over the alternatives $\{\mathrm{I}, \mathrm{C}, \mathrm{ND}\}$. These implications are contained in Table 1 where notation is simplified by suppressing the subscript, $\mathrm{p}$. The striking thing about Table 1 is the perfect symmetry which exists even under the asymmetric assumption of incumbent effectiveness. For every preference ordering which produces a preference for the incumbent, there is a "mirror image" which produces a preference for the challenger. Even the two indeterminate cases contain a curious symmetry: the comparative statics are precisely opposite. That is, if $\mathrm{U}\left(\mathrm{C}_{\mathrm{p}}\right)>\mathrm{U}\left(\mathrm{I}_{\mathrm{p}}\right)>$ $\mathrm{U}$ (ND), increased incumbent effectiveness is more likely to produce an incumbent preference (the citizen may prefer a second choice who is more effective). But if $\mathrm{U}(\mathrm{ND})>\mathrm{U}(\mathrm{I})>\mathrm{U}(\mathrm{C})$, increased incumbent effectiveness is less likely to produce an incumbent preference. 
The underlying basis for all this symmetry is clear upon a moment's reflection. Incumbent effectiveness is a two-edged sword. Those who favor the incumbent's platform (relative to the $\mathrm{C}$ and ND alternatives) naturally value incumbent effectiveness. But those who dislike the incumbent's position to the extent that they would prefer the position of the rest of the legislature do not attach positive value to incumbent effectiveness. Quite the contrary. They would sooner countenance an incompetent challenger than an effective incumbent whose policies they loathe. In short, incumbency effectiveness does not translate directly into incumbency advantage.

There is a variety of perspectives from which to view Table 1 . One of the most interesting is from the point of view of a world in which policy preferences are randomly distributed. If we were to take 100,000 citizens (a low estimate of average turnout in an off-year American election) and assign them values of $U\left(I_{p}\right)$, $\mathrm{U}\left(\mathrm{C}_{\mathrm{p}}\right)$, and $\mathrm{U}(\mathrm{ND})$ on a random basis, then have them vote in accord with $3 \mathrm{a}$ and $3 \mathrm{~b}$, the expected outcome of the election would be a tie. Thus, the incumbency advantage is not the simple result of incumbent effectiveness.

Random worlds aside, a second possible perspective is that taken by existing models of electoral competition. What happens when a majority rule equilibrium exists? When one does not? To address these questions it is necessary to make a rather strong assumption: all citizens in a district form the same estimates of legislative output when their representative makes no difference, i.e., all citizens agree upon the policies signified by ND (they may of course differ about the desirability of ND).

If a majority rule equilibrium exists, electorally rational candidates choose it. Thus, assuming the equilibrium is distinct from $\mathrm{ND}$, only three preference patterns are present in the electorate:

$$
\begin{aligned}
& \mathrm{U}\left(\mathrm{I}_{\mathrm{p}}\right)=\mathrm{U}\left(\mathrm{C}_{\mathrm{p}}\right)>\mathrm{U}(\mathrm{ND}) \Rightarrow \mathrm{U}(\mathrm{ND}) \Rightarrow \text { indifference } \\
& \mathrm{U}\left(\mathrm{I}_{\mathrm{p}}\right)=\mathrm{U}\left(\mathrm{C}_{\mathrm{p}}\right)=\mathrm{U}\left(\mathrm{I}_{\mathrm{p}}\right)=\mathrm{U}\left(\mathrm{C}_{\mathrm{p}}\right) \Rightarrow \text { prefer } \mathrm{C} \\
& \mathrm{U}(\mathrm{ND})>\mathrm{U}
\end{aligned}
$$

From the definition of a majority rule equilibrium a minority of citizens has the third ordering. ${ }^{19}$ Moreover, assuming indifferents split their vote exactly 50-50, the definition precludes the third group

19 If a majority had the third ordering, ND would be majority preferred to I and C, contrary to the definition of a majority rule equilibrium. 
from being larger than the first. Thus incumbency effectiveness gives the incumbent an edge.

In the much more likely case of no majority rule equilibrium, the incumbent, who moves first in the electoral game (by casting roll call votes, for example), can be outmaneuvered by the electorally rational challenger. Thus, a majority of citizens has one of the following preference orderings:

$$
\left.\begin{array}{l}
\mathrm{U}\left(\mathrm{C}_{\mathrm{p}}\right)>\mathrm{U}(\mathrm{ND}) \geq \mathrm{U}\left(\mathrm{I}_{\mathrm{p}}\right) \\
\mathrm{U}(\mathrm{ND}) \geq \mathrm{U}\left(\mathrm{C}_{\mathrm{p}}\right)>\mathrm{U}\left(\mathrm{I}_{\mathrm{p}}\right)
\end{array}\right\} \begin{aligned}
& \text { which produce } \\
& \text { challenger preferences }
\end{aligned}
$$

In this case the incumbent can win only if the third category is sufficiently numerous and sufficiently responsive to incumbent effectiveness to deny the challenger a majority. And what is the incumbent's strategy? Those in the third category are susceptible to arguments for incumbency effectiveness-campaigns based on experience, seniority and the like. But remember, there is a "mirror image" category $(\mathrm{U}(\mathrm{ND})>\mathrm{U}(\mathrm{I})>\mathrm{U}(\mathrm{C}))$, some of whom are already in the incumbent's camp, who will be repelled by that very strategy. In sum, given the likely nonexistence of a majority rule equilibrium, the electoral prospects of the incumbent are not generally predictable; they depend on the precise configuration of voter preferences.

All of the foregoing can be summarized in a fairly simple statement. In a full information model of competition for legislative office, where competition is restricted to the policy domain, and incumbents are more effective than challengers in influencing policy, incumbency carries no general electoral advantage.

\section{The Pork Barrel Component of Legislative Voting}

Once a program is in operation the concern of the legislator may change. The costs of national activities are spread across all districts but the benefits typically can be and are appropriated by specific areas and/or groups. Whether a particular legislator favors the virtually unlimited construction of water treatment plants, for example, once the legislature has made that decision a legislator should attempt to procure as many plants for his or her district as possible. After all, construction of the plants creates jobs and perhaps cleaner water, most of which will be paid for by taxes raised 
in other districts. In addition, the plants serve as visible reminders of the efforts of the legislator on behalf of the district.

In the pork barrel sphere the informed voter has no difficulty in specifying the ND outcome: nothing. In the legislature it is every district for itself. If one's representative does not bring home the bacon, no one does. This fact severely restricts the domain of reasonable preferences for the informed voter: some is better than none. The incumbent and challenger may have a different emphasis ( urban pork vs. rural pork, construction pork vs. services pork, etc.), but the pork package advocated by either should be preferred to the ND outcome which is simply no benefits with virtually the same taxes. ${ }^{20}$ Thus, the citizenry will fall into the following two categories:

$$
\begin{aligned}
& \mathrm{U}\left(\mathrm{I}_{\mathrm{b}}\right) \geq \mathrm{U}\left(\mathrm{C}_{\mathrm{b}}\right)>\mathrm{U}(\mathrm{ND}) \\
& \mathrm{U}\left(\mathrm{C}_{\mathrm{b}}\right)>\mathrm{U}\left(\mathrm{I}_{\mathrm{b}}\right)>\mathrm{U}(\mathrm{ND})
\end{aligned}
$$

If we let $b\left(I_{b}\right)$ and $b\left(C_{b}\right)$ denote the incumbent's and challenger's respective probabilities of delivering the benefits they promise, the expected utility of the incumbent from pork barrel programs, $\operatorname{EU}\left(I_{p}\right)$, exceeds that of the challenger, $\operatorname{EU}\left(C_{b}\right)$, if

$$
\frac{b\left(I_{b}\right)}{b\left(C_{b}\right)}>\frac{U\left(C_{b}\right)-U(N D)}{U\left(I_{b}\right)-U(N D)}
$$

Again we assume incumbent effectiveness:

$$
\mathrm{b}\left(\mathrm{I}_{\mathrm{b}}\right)>\mathrm{b}\left(\mathrm{C}_{\mathrm{b}}\right) .
$$

All citizens with the first preference ordering listed in (4) satisfy (5), i.e., prefer the incumbent. In addition some of those with the second ordering also satisfy (5). Moverover, as the relative effectiveness of the incumbent increases, the proportion of voters with the second ordering who will vote for the incumbent will also increase.

20 The reader no doubt can recall some well publicized examples in which a pork barrel project became a major issue. We concede that exceptions to the general argument exist. But legislators generally avoid pork barrel activities which will arouse opposition within their districts. This means that different legislators emphasize different aspects of the pork barrel, e.g., dams and other construction in one district, health centers in others, defense contracts in still others, etc. 
Considering a random world again, the conclusion for the pork barrel component of an election is different from that suggested for the policy component. With randomly assigned preferences (subject to the restrictions embodied in (4), the incumbent would expect a minimum of half the votes, expecting a vote proportion in the interval $[.5,1.0]$ rather than exactly at .5 as previously. This advantage results directly from the relatively greater homogeneity of preferences in the pork barrel sphere. All constituents would rather have something than nothing, so to speak.

If a majority rule equilibrium exists in the pork barrel arena,

$$
\mathrm{U}\left(\mathrm{I}_{\mathrm{b}}\right)=\mathrm{U}\left(\mathrm{C}_{\mathrm{b}}\right)>\mathrm{U}(\mathrm{ND}) \text { for all citizens, }
$$

and the incumbent is unanimously preferred. If there is no majority rule equilibrium, the incumbent can be outmaneuvered so that for a majority,

$\mathrm{U}\left(\mathrm{C}_{\mathrm{b}}\right)>\mathrm{U}\left(\mathrm{I}_{\mathrm{b}}\right)>\mathrm{U}(\mathrm{ND}) \Rightarrow$ indeterminate preference

while for the remainder,

$$
\mathrm{U}\left(\mathrm{I}_{\mathrm{b}}\right)>\mathrm{U}\left(\mathrm{C}_{\mathrm{b}}\right)>\mathrm{U}(\mathrm{ND}) \Rightarrow \text { prefer } \mathrm{I} \text {. }
$$

The incumbent can win if enough of those in the first category prefer a more effective second choice to a less effective first choice. Ceteris paribus, the greater is the relative effectiveness of incumbents, the greater is the likelihood that "enough" of those in the first category will prefer the incumbent to the challenger.

The upshot of all this is clear. If we were incumbents, we would rather campaign on pork than on policy, unless we had some prior assurance that policy preferences would be as homogeneous as pork preferences are expected to be.

\section{The Casework or Service Component of Legislative Voting}

The service component is essentially the same as the pork barrel component. The incumbent and challenger may differ in emphasis, but the package of ombudsman services offered by either is preferred to the ND outcome, which again is no services. In the U.S., for example, if your representative will not oblige you by tracking down a lost social security check or interceding with OSHA, no one else will. Thus, the informed citizen should have one of the following two preference orderings for packages of services: 


$$
\begin{aligned}
& \mathrm{U}\left(\mathrm{I}_{\mathrm{s}}\right) \geq \mathrm{U}\left(\mathrm{C}_{\mathrm{s}}\right)>\mathrm{U}(\mathrm{ND}) \\
& \mathrm{U}\left(\mathrm{C}_{\mathrm{s}}\right)>\mathrm{U}\left(\mathrm{I}_{\mathrm{s}}\right)>\mathrm{U}(\mathrm{ND})
\end{aligned}
$$

If we let $s\left(I_{s}\right)$ and $s\left(C_{s}\right)$ stand for the incumbent's and challenger's respective probabilities of delivering their promised package of services, the expected utility of the incumbent from services, $\mathrm{EU}\left(\mathrm{I}_{\mathrm{s}}\right)$ exceeds that of the challenger, $\mathrm{EU}\left(\mathrm{C}_{\mathrm{s}}\right)$ if

$$
\frac{\mathrm{s}\left(\mathrm{I}_{\mathrm{s}}\right)}{\mathrm{s}\left(\mathrm{C}_{\mathrm{s}}\right)}>\frac{\mathrm{U}\left(\mathrm{C}_{\mathrm{s}}\right)-\mathrm{U}(\mathrm{ND})}{\mathrm{U}\left(\mathrm{I}_{\mathrm{s}}\right)-\mathrm{U}(\mathrm{ND})}
$$

As in the pork barrel case the incumbent would have an expectation in the interval $[.5,1.0]$ if the service component alone were operating in a random world. If a majority rule equilibrium exists, the incumbent would win a unanimous victory. If no such position exists, the incumbent should stress effectiveness. Again, if we were incumbents who wished to stay incumbents, we would rather run as ombudsmen than as the architects of national policy.

\section{Summary of the Voting Model}

In the preceding pages we have tried to develop a model which would allow incumbents an edge in legislative elections rather than place them at a disadvantage as interpretations of existing models seem to do. Our model differs from its forerunners in two respects. First, it recognizes the varied nature of legislative activity. The formulation of national policy is not the only task engaged in by contemporary legislators. Constituents expect other things as well, and these other expectations are likely to be more homogeneous than those concerning policy formation. Second, our model recognizes that election of a legislator is not equivalent to selection of a policy program; election only sends legislators into another game with other elected candidates. Thus, in legislative elections citizens are choosing between platforms which will be realized only probabilistically. And in very large legislatures (especially in systems with independent executives) these probabilities will generally be very small. As a result, voters must consider what happens in the event that neither contending candidate is effective, a third prospect not apparent in models of two candidate competition for executive office. Moreover, in choosing between two legislator-lotteries citi- 
zens presumably are discerning enough to recognize that experience in holding office has certain consequences. Is it not reasonable to assume that a subcommittee chairman with six years experience will be more effective than a freshman Republican, for example? We have shown that the interaction between incumbent effectiveness and preference homogeneity generates an incumbency advantage. Interestingly, however, where preferences are heterogeneous, as they may be in the policy realm, incumbency effectiveness cuts both ways.

\section{IMPLICATIONS OF THE THEORY}

One mark of a useful theory is its ability to illuminate facts beyond those it was constructed to explain. In this section we discuss a variety of empirical hypotheses implied by our model of legislative voting. These hypotheses fall into two categories: process implications and policy implications.

\section{Process Implications}

The model suggests that incumbents will place a heavy emphasis on project, grant, and service activities in their electoral campaigns, because it is in these areas that incumbency generates an electoral advantage. Thus, we expect incumbent advertising to focus heavily on the aforementioned activities. It is no accident, for example, that even conservative U.S. Representatives herald their success in bringing federal monies to their districts. ${ }^{21}$ Moreover, we should observe incumbents attempting to project an image of concern with the personal problems of constituents, and of willingness to help with such problems. Fenno has noted congressional incumbents' efforts to build feelings of generalized trust and accessibility among constituents. ${ }^{22}$ Our argument implies that incumbents are not just playing on affective feelings on the part of their constituents. In addition, they may be rationally encouraging constituents

21 When Representative Burt Talcott (Republican, California) found himself in a tough race in 1976 he pitched his campaign around the theme that his Monterey district ranked third among 435 congressional districts in receipt of federal money. Talcott's 1976 ADA score was ten. He lost the election but the strategy was clear.

22 Richard F. Fenno, Home Style: House Members in Their Districts (Boston: Little, Brown \& Company, 1978) 54-60, 131-135, and passim. 
to form high estimates of incumbent effectiveness in an area (personal servicing) where high estimates lead to electoral successes. Only when issue positions enjoy overwhelming majority support among constituents should we observe incumbent emphasis on issues. It is easy and safe to be policy oriented if one is on the right side of an 80:20 split.

A second set of process implications concerns comparisons across legislatures. Although legislative incumbents in general are expected to shy away from an issue emphasis relative to a service and project emphasis, certain features of legislatures may reinforce that tendency. For example, in the U.S. House we find a strong committee system, the components of which are relatively autonomous when overseeing the bureaucracy, but much less so when drawing up national policy. Thus, for the typical U.S. representative, $\mathrm{b}(\mathrm{I})>\mathrm{p}(\mathrm{I}), \mathrm{s}(\mathrm{I})>\mathrm{p}(\mathrm{I})$, providing all the more reason for a project and service emphasis. In contrast, legislatures with a weak or nonexistent committee system (such as the British Parliament) provide a more balanced incentive system to their members and in turn to their electorates. In proportional representation (PR) systems the model ceases to apply. In a PR system projects and services may provide benefits to a party, but not directly to a particular legislator. As with public goods generally, individuals will tend to shirk the cost of providing the general (i.e. party) benefit. Thus, legislative systems probably can be arrayed along a rough continuum according to the incentives they provide their members and voters to emphasize distributive policies and individual services relative to policy formation.

A third set of process implications follows from a consideration of estimates of incumbency effectiveness. Other things equal the size of the incumbency advantage should vary with certain objective characteristics of incumbents. Most obviously, members of an apparently permanent majority party should have an even greater advantage. Voters will realize that the minority party candidate has little chance to implement a policy proposal. And when voters turn to the project and service components, the majority party candidate - especially if incumbent-will typically have the advantage there because the majority controls the committee structure. Once the legislative party balance appears to depart permanently from an even split, the incentives facing voters will lead to eventual eradication of the minority party unless some exogeneous shock to the system overrides the micro-motives we have identified. 


\section{Policy Implications}

If the theory developed in section II accurately describes certain aspects of electoral reality, three public policy tendencies should exist. For shorthand we refer to these as the bureaucratic tendency, the distributive tendency, and the growth tendency. We stress the use of the term "tendency." Public policy will be more bureaucratically organized, more distributive in nature, and more extensive in scope than it would be in the absence of a legislative incumbency advantage, but the theory does not enable us to say how much more - perhaps a little bit, perhaps a lot. Moreover, while these tendencies constitute inefficiencies or costs associated with an incumbency advantage, any ultimate assessment of net impact should take account of positive aspects of service and project activities as well. The expertise and influence of a representative in speeding bureaucratic actions and lowering the cost of dealing with government have some value to society. Nevertheless, an incumbency advantage arising from service and project activities does change the nature of democratic government in potentially troubling respects.

\section{The Bureaucratic Tendency}

Because of the electoral advantage arising from influence over the bureaucracy incumbents should hestitate to create programs which are beyond discretionary control. In practice this means that programs will require more in the way of bureaucratic inputs than might be ideal. The point is best illustrated by American examples. There is something to be said for razing the present jerry-built structure of income security programs and replacing it with a guaranteed annual income implemented entirely through the tax laws. The marginal cost of expanding IRS would be less than the savings accomplished by closing down numerous existing transfer programs. Similarly, we might eliminate the congeries of federal grant-in-aid programs to states and localities and replace it with general revenue sharing. As before, the bureaucratic savings are manifest. In each of these cases there are arguments on both sides, of course, but one argument that is seldom recognized is the congressional stake in maintaining the more bureaucratic way of doing things. Naturally, legislators dislike the uncertainty attendant upon any major program shift. But beyond that, if benefits are distributed automatically (through tax refunds, quarterly revenue-sharing checks, etc.) constituents may come to expect them as their due and not regard them, 
at least in part, as the gift of benevolent legislators. And if costs are imposed automatically (tax payments), fewer citizens are likely to seek the aid of their representative in efforts to avoid those costs.

\section{The Distributive Tendency}

This second tendency is related to the first. Again, let us consider American examples. There is widespread agreement among professional economists that tax schemes are superior to subsidies and mandatory standards as means of attacking some important pollution problems. Yet one of the most popular congressional programs provides localities with grants to construct water treatment plants to conform to congressionally mandated standards. ${ }^{23}$ The Model Cities program, originally conceived as a demonstration project in a handful of carefully selected locations, was quickly extended to a pork barrel program for hundreds of communities, many of which were not even cities. ${ }^{24}$ The common thread in such examples is the distributive tendency.

Put most simply, representatives favor federal programs whose effects appear as federal (i.e. congressional) "gifts" to their districts. Building thousands of sewage treatment plants may be an uneconomic way of cleaning up our nation's water, but the political benefits are no doubt positive. while taxing those who spoil the water might entail a net political cost. Similarly, spreading Model Cities projects around the country was the cost of getting any program at all through Congress. These and other distributive policies may create the illusion that the district has gotten something that the rest of the country has paid for; universal taxes or benefits are less likely to create such illusions.

Lowi argues that political science operates according to the axiom that "policy determines politics." 25 His observation is insightful but we should recognize too that politicians prefer some kinds of politics to others. In particular, passing out federal plums is more pleasant than reforming the nation's tax laws. Redistribu-

${ }^{23}$ These are the water treatment plant construction grants now authorized by the Clean Water Act of 1972 and administered by the Environmental Protection Agency.

${ }^{24}$ For a discussion of the Model Cities Program, see Randall Ripley, The Politics of Economic and Human Resources Development (Indianapolis, Ind.: Bobbs-Merrill, 1972), Ch. 5.

25 Theodore Lowi, "Four Systems of Policy, Politics and Choice," Public Administration Review, (1972), 298-310. 
tive policy creates a kind of politics different from distributive policy, a more difficult and dangerous kind of politics, and for that reason politicians prefer the latter arena to the former.

Recall the old concept of the "life cycle" of an issue. Issues arise from the agitation of intense minorities, some eventually become the subject of national debate, and some of these eventually become public policy after a difficult fight. But then the policy supposedly becomes widely accepted-"legitimated" is the term often applied -and controversy wanes. One explanation is that opponents of the policy see its worth after it is implemented. An alternate account is that great issues typically arise in the redistributive or regulatory arenas. By the time they become law, however, they are heavily infused with distributive elements in order to buy critical congressional support. This transition from regulatory or redisributive policy to distributive then continues as the policy is administered. Controversy wanes precisely because the class of beneficiaries grows so large. Stockman describes just such a process in his discussion of the "social pork barrel." 26 Republicans who originally went to the mat against various Great Society programs quietly voted for renewal when the programs came up for reauthorization.

To return to the general point, the distributive tendency seems to be a natural concomitant of our theory. When the choice is available, legislatures should prefer to structure programs so that decisions are project-by-project, or grant-by-grant. Automatic distribution according to a fixed formula is not nearly so attractive politically. Perhaps an underemphasized reason for Lyndon Johnson's success in steering Great Society programs through Congress was his appreciation for and willingness to use distributive politics to purchase congressional support. ${ }^{27}$ Correspondingly, failure to appreciate ( or unwillingness to deal with) distributive policymaking may be one of Carter's principal problems vis-à-vis his party in Congress. ${ }^{28}$

One final remark. The distributive tendency no doubt reinforces

26 David Stockman, “The Social Pork Barrel," Public Interest (1975), 3-30.

27 At the beginning of Johnson's administration exactly two-thirds of all federal grants were project grants (the remainder being formula grants). During the three-year period 1964-66 over 80 percent of new grant programs were of the project variety. See Advisory Commission on Intergovernmental Relations, Fiscal Balance in the American Federal System 1 (October 1967), 151.

${ }^{28}$ Eric Davis, "Legislative Liaison in the Carter Administration," Political Science Quarterly, 95 (1979), 287-301. 
the bureaucratic tendency. Project-by-project decisions require more bureaucratic resources than automatic distribution programs. Additionally, once a program is enacted, the game changes. Continued opposition to a program would only succeed in penalizing one's district, not'as a result of direct bureaucratic action, but by foregoing what would be one's due under the (increasingly distributive) program. In short, incentives change after a policy is implemented. Given that a program will be enacted, a representative faces better reelection prospects if the program is designed to be distributive in nature and bureaucratic in administration.

\section{The Growth Tendency}

This third tendency is in part a consequence of the preceding two, and in part a consequence of factors not explicitly included in the theory. Stated simply, our model suggests that a legislative incumbency advantage contributes to a larger public sector. In explaining why, it is useful to recognize at least three dimensions of government growth.

First is the size of the bureaucracy for any given level of public activity. The bureaucratic and distributive tendencies contribute to growth along this dimension. To the extent that legislatures choose policy instruments which entail a larger commitment of personnel and resources than is necessary, the size of the government establishment is larger.

Second is the intrusiveness of government activity. Bureaucratic means of implementing programs impose a burden on citizens-the burden of providing detailed information to the bureaucratic decisionmaker, and then waiting for a decision. For example, a guaranteed annual income seems rather less intrusive than proving eligibility for the numerous income supplement/security programs now in existence. General revenue sharing seems less burdensome to local government than applying for numerous categorical grants. A tax to curtail energy use, perhaps returned by reductions in other taxes, is simpler for all concerned than detailed regulations regarding "entitlements" to domestic oil, conversion of certain boilers to use coal, and mandatory gas curtailments for particular types of users. Again, the bureaucratic and distributive tendencies appear to contribute to a more intrusive kind of government than would otherwise be the case.

Finally, a third aspect of size is an expansion in the scope of government activity, which occurs when the government chooses to 
regulate an area not previously regulated, subsidize a sector not previously subsidized, tax something not previously taxed, etc. What does our model say about this third kind of government growth? As representatives increasingly attain reelection on the basis of their broker and ombudsman roles, programmatic electoral accountability as traditonally conceived weakens. That is, incumbents have less need to hew closely to the policy positions of their constituents if the latter do not vote on the basis of such positions. ${ }^{29}$ As the policy ties loosen, what do representatives do with their increased Alexibility? The model addresses only one aspect of that question-we have given our theoretical representatives no preferences other than reelection, and that only narrowly defined. It would be natural, however, to expand the model to have representatives take a broader view of their personal interests. For example, they might use their policy freedom to maximize campaign contributions and other political resources from well-organized groups. In principle, such efforts need not lead to government growth. But we suspect that the preponderance of demands on government takes the form of requests for additional government activity-new regulations for consumerists, environmentalists, and good government types, new subsidies and/or tariffs for business interests, new licensing provisions for various professional groups, new grant programs for common interest groups of all types, and so forth. Thus, to the extent that representatives are free to depart from close agreement with their constituents, the existing pressures appear to suggest departures in the direction of expanding the sphere of government activity.

\section{Summary}

The implications of our theory of legislative voting are highly speculative but potentially important. In addition to a "rich get

\footnotetext{
29 Elsewhere we prove that (1) the vote-maximizing policy position for an incumbent is for a larger public sector than is the vote-maximizing stance for a challenger; and (2) an incumbent can deviate from the vote-maximizing policy position in any direction by some amount and still win, given vote-maximizing behavior by the challenger, as long as incumbents are expected to be better facilitators and ombudsmen than are challengers. The second point is the source of some uncertainty as to whether the model we have developed leads to a more extensive public sector than traditional issue-based democratic theory. See Fiorina and Noll, "Voters, Bureaucrats and Legislators: A Rational Choice Perspective on the Growth of Bureaucracy," Journal of Public Eco nomics 9 (1978) 1-16.
} 
richer" relationship between legislative majorities and minorities, we expect a systematic bias against certain types of policy instruments which may well be more efficacious than those actually chosen. Consequently, societies may experience a shortfall in public policy accomplishments which could contribute to increasing cynicism about the potential of democratic government. The same biases work toward the adoption of public policies which impinge on individual behavior more than is necessary and could thus contribute to an increasing resentment of government activity, per se. Finally, though democratic politicians may decry big government, their individual, uncoordinated actions in support of their electoral interests contribute to that which they decry. The paradox is that at least in the short term these systemically troublesome features of legislative electoral arenas benefit the politicians who participate in them.

\section{Conclusion}

In contrast to traditional models of electoral competition, we find nothing mysterious about incumbent success in legislative elections. To the extent that representatives act as ombudsmen and pork barrelers rather than policymakers, their political experience and formal positions give voters a legitimate reason to support them over inexperienced challengers, even if the latter offer somewhat more attractive positions on issues. But we caution that the individual rationality of the voter combined with the individual rationality of the candidates need not produce a government which is the embodiment of collective rationality. We have suggested several ways in which myopic individual rationality can produce systematic biases against particular classes of public policy instruments. Moreover, we have observed that an incumbency advantage based on constituency service may weaken electoral accountability as traditionally conceived. The implications of such observations are neither fully worked out nor verified as yet, but the questions raised deserve attention. 


\section{APPENDIX: \\ The Basic Logic of Majority Rule Processes}

This appendix provides an informal elaboration of the introductory remarks for the benefit of the general reader. By now most political scientists are familar with Downs' analysis of party competition in a one-dimensional policy space. Given single-peaked preferences, and universal voting, the ideal point (i.e. most preferred position) of the median voter is the majority rule equilibrium. ${ }^{30}$ When the policy space is of more than one dimension, however, this determinate result disappears.

Consider Figure 1 which represents views from above a twodimensional policy space. Voters have unimodal preferences in this space such that the "farther" a position from their ideal point, the less they prefer it. Levels of preference are represented by indiffurence curves with outer curves indicating lower preference than inner curves. The analogy is to a topographical map where outer contours indicate lower elevations than inner contours. Points from which the indifference curves radiate are the voter maxima, or ideal points. Typically, assumptions are made about the shape of voter preferences. Convexity is a standard assumption. An indifference curve is convex if a line joining any two points on the curve lies entirely within the area circumscribed by the curve (a circle is convex, a figure eight is not). The case in which indifference curves are concentric circles is particularly simple; given any two points a voter with such preferences votes for the one that is closer to his ideal point. One can determine preference by use of a ruler or compass in this situation.

In the top illustration in Figure 1 the ideal point of voter $I$ is the majority rule equilibrium: it is closer to at least three voters (including voter 1 ) than any other point with which it might be compared. Note how all voters other than \#1 are divided into opposing pairs. This is an informal rendering of Plott's conditions for the existence of a majority rule equilibrium.

Now consider the second illustration which differs from the first only in that voter \#1 is placed a bit northeasterly from where he was previously. This slight movement destroys the equilibrium: no point in the space is closer to at least three voters than is any

${ }^{30}$ Downs, An Economic Theory, Ch. 8. Downs' analysis is an application of Black's median dominance theorem. See "On the Rationale of Group Decision Making." 


\section{Figure 1}
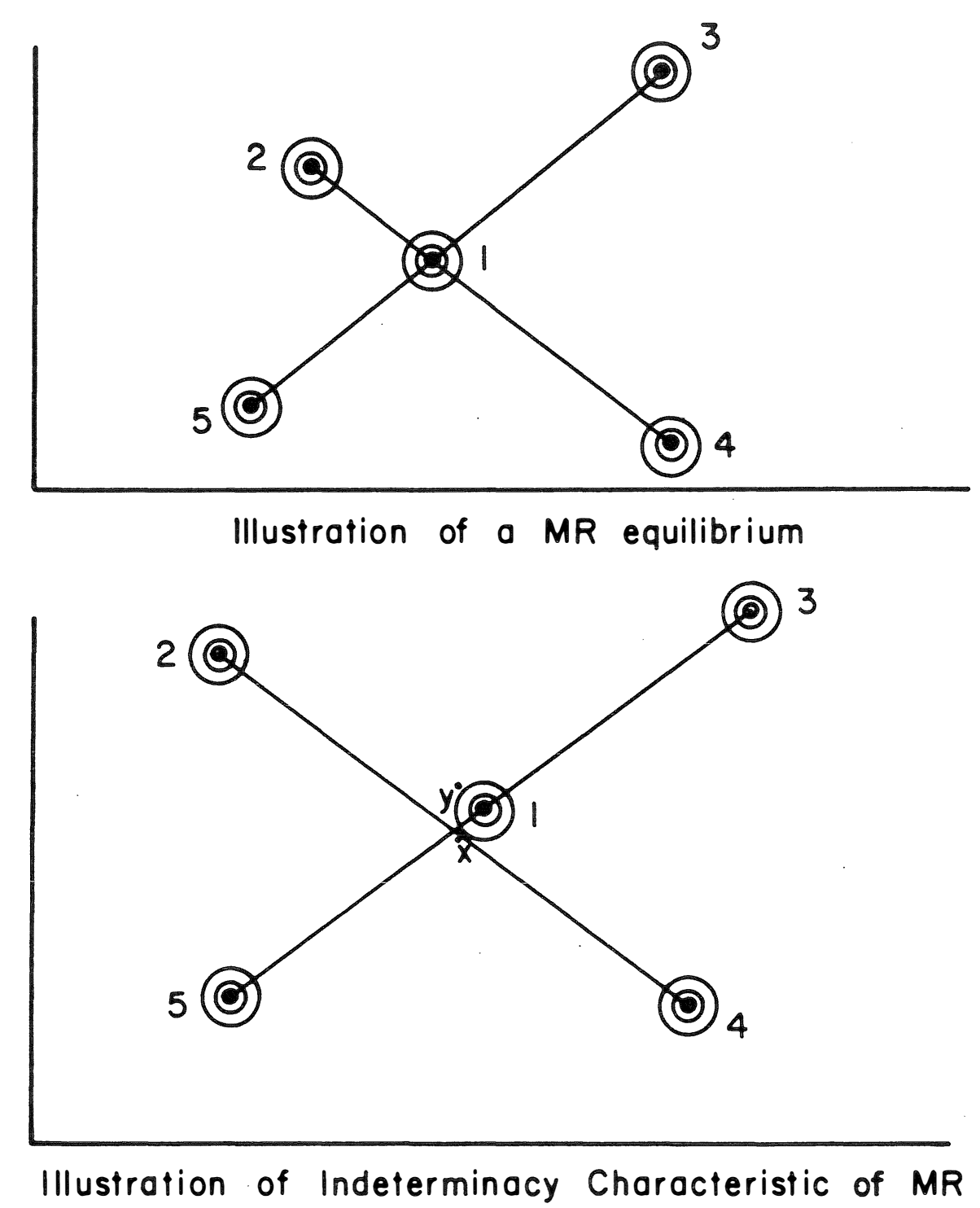

other point with which it might be compared. For example, voter l's ideal point would lose to position $\mathrm{x}$ by the votes of 2,4 , and 5 . (The reader might verify this claim with a compass.) Position $\mathrm{x}$ in turn would lose to position y by the votes of 1,2 , and 3 . And so on, forever. The work of McKelvey, Schofield, Cohen, and Cohen and Matthews demonstrates that the second illustration is the norm and 
the first the rare exception. The kinds of balancing conditions which underlie equilibrium seem exceedingly unlikely to hold in a reasonably differentiated policy space with large numbers of voters. And in the absence of such regularities majority rule is completely unconstrained: outcomes will be artifacts of the specific rules and procedures which determine the order of consideration of proposals, and these outcomes may vary wildly with such factors. ${ }^{31}$

31 As shown in Charles Plott and Michael Levine, "A Model of Agenda Influence on Committee Decisions," American Economic Review 68 (March 1978) 146. 